\title{
Patterns of hobo elements and their effects in natural populations of Drosophila melanogaster in Japan
}

\author{
K Kikuno ${ }^{1,4}$, K Tanaka ${ }^{1,5}$, M Itoh ${ }^{2}$, Y Tanaka ${ }^{1}$, IA Boussy ${ }^{3}$ and S Gamo ${ }^{1}$ \\ ${ }^{1}$ Department of Earth and Life Sciences, Osaka Prefecture University, 1-1 Gakuen-Cho, Sakai 599-8531, Japan; ${ }^{2}$ Department of Applied \\ Biology, Kyoto Institute of Technology, Kyoto 606-8585, Japan; ${ }^{3}$ Department of Biology, Loyola University of Chicago, Chicago, \\ IL 60626, USA
}

\begin{abstract}
We studied the dynamics of hobo elements of Drosophila melanogaster in Japan with the goal of better understanding the invasion and evolution of transposons in natural populations. One hundred and twenty-six isofemale lines and 11 older stocks were tested for the presence and genetic phenotype of hobo elements. The oldest $\mathrm{H}$ strain, containing complete and deleted hobo elements, is Hikone-H (1957), but Hikone-R (1952) has no hobo-homologous sequences. The findings suggest that the hobo element invaded Japanese populations in the mid-1950s, at about the same time as the $P$ element invasion in Japan. This chronology is consistent with the hypothesis of a recent worldwide hobo element invasion into $D$. melanogaster in the mid-1950s. In recently collected populations, $\mathrm{H}^{\circ}$ strains (low hobo activity and high repression potency) are predominant, whereas $\mathrm{H}^{+}$ strains (high hobo activity and high repression potency) are
\end{abstract}

predominant in the Sakishima Islands, the most southwestern islands of the Japanese archipelago. $\mathrm{H}^{\prime}$ strains (high hobo activity and low repression potency) were first found in limited island populations. Japanese populations have not only full-size hobo elements and $1.5 \mathrm{~kb}$ Th elements but also characteristic deletion derivatives (1.6 and $1.8 \mathrm{~kb}$ Xhol fragments) that we have named $J h$ elements. These results are consistent with transgenic experiments with complete hobo elements, in which populations evolved to $\mathrm{H}^{+}$or $\mathrm{H}^{\circ}$ via $\mathrm{H}^{\prime}$, and in which $1.8 \mathrm{~kb}$ fragments appeared. We conclude that hobo elements invaded the central region of Japan, spread to the far islands, and that the invasion is currently at an intermediate, nonequilibrium stage.

Heredity (2006) 96, 426-433. doi:10.1038/sj.hdy.6800816; published online 26 April 2006

Keywords: Drosophila melanogaster, hobo element; Japan; natural population

\section{Introduction}

The spread of selfish genetic elements and parasites, such as transposons and Wolbachia (rickettsial endosymbiont; Boyle et al, 1993), has been described for a number of systems, especially in Drosophila melanogaster populations. In D. melanogaster, about 50 families of transposable elements are known, divisible into at least three groups according to their DNA structure and putative mechanisms of transposition (Finnegan, 1992). Type II elements that have short terminal inverted repeats and transpose directly from DNA to DNA include hobo, $P$, pogo, and $H B$ elements. Active hobo elements are known to induce a suite of anomalies, termed hybrid dysgenesis, as are $P$ and I elements (Kidwell, 1979). The symptoms of hobo hybrid dysgenesis include gonadal dysgenesis (GD), chromosomal aberrations, high mutation rates, and male recombination in the germ line of the hybrid progeny

Correspondence: S Gamo, Department of Earth and Life Sciences, Osaka Prefecture University, 1-1 Gakuen-Cho, Sakai 599-8531, Japan.

E-mail: gamo@las.osakafu-u.ac.jp

${ }^{4}$ Current address: Department of Biochemistry and Cellular and Molecular Biology, University of Tennessee, Knoxville, TN, USA.

${ }^{5}$ Current address: Graduate School of Molecular Biology, Nara Institute of Science and Technology, Nara, Japan.

Received 19 August 2005; accepted 16 February 2006; published online 26 April 2006 from a dysgenic cross (Lim, 1979; Yannopoulos et al, 1983, 1987; Blackman et al, 1987). The hobo element was first cloned and characterized by McGinnis et al (1983). Calvi et al (1991) sequenced a functional hobo element (HFL1) that was $2959 \mathrm{bp}$ long, with a $2.0 \mathrm{~kb}$ ORF. The large ORF (ORF1) polypeptide sequence has strong similarity to the Ac (Zea mays) and Tam3 (Anthirrinum majus) transposases; this similarity is the basis for describing the hobo-Ac-Tam (hAT) family (Calvi et al, 1991). The family has representatives in other drosophilid and nondrosophilid insects (Warren et al, 1994) and in Caenorhabditis elegans (Bigot et al, 1996).

The distributions of hobo elements in natural populations have been examined previously (Yannopoulos et al, 1983, 1987; Streck et al, 1986; Periquet et al, 1989a,b). Strains collected before the mid-1950s lack hobo elements (E strains), while recently collected ones have complete and defective derivatives ( $\mathrm{H}$ strains). These surveys revealed the presence of locally characteristic defective hobos, for example, the $1.5 \mathrm{~kb}$ Th elements, first found in Eurasian populations (Periquet et al, 1989a), the $1.9 \mathrm{~kb} \mathrm{Oh}$ element in the Oregon- $\mathrm{R}^{\mathrm{s}}$ strain (Pascual and Periquet, 1991), and the $1.7 \mathrm{~kb}$ Kh elements in Korean strains (Kim and Kim, 1999). Also shown in all strains tested was the presence of hobo-hybridizing sequences that generate high molecular weight $(>3 \mathrm{~kb})$ XhoI fragments (Streck et al, 1986; Boussy and Daniels, 1991; Pascual 
and Periquet, 1991; Boussy and Itoh, 2004). Several hobo-homologous sequences were identified in the euchromatin (Galindo et al, 2001) and heterochromatin of E strains (Boussy and Itoh, 2004). It is hypothesized that hobo elements were introduced into the melanogaster group ancestor twice (Daniels et al, 1990; Boussy and Itoh, 2004). In order to understand how the canonical hobo elements evolves and how they can influence the hobo activity, several transgenic experiments with complete hobo elements have carried out (Galindo et al, 1995; Ladeveze et al, 1998, 2001; Souames et al, 2003a, b). After complete hobo elements are introduced into an E strain, the populations are $\mathrm{E}^{\prime}$ (low hobo activity and low hobo repression potency), become $\mathrm{H}^{\prime}$ (high hobo activity and low repression potency), until evolving an $\mathrm{H}^{+}$(high hobo activity and high repression potency) or an $\mathrm{H}^{\circ}$ (low hobo activity and high repression potency) phenotype (Galindo et al, 1995). XhoI fragments (1.8 kb), indicating internal deletions in hobo elements, appeared independently in transgenic lines of complete hobo elements at different generations. Lines were found to evolve to one of three patterns of hobo-homologous sequences: containing only full-size elements; containing only deleted elements; or containing both full-size and deleted sequences (Souames et al, 2003a,b). It is assumed that similar dynamics occur when hobo elements invade natural populations.

We have examined the dynamics of hobo elements in Japanese natural populations of laboratory-maintained strains of $D$. melanogaster collected in various parts of Japan from 1952 to 1989 (Gamo et al, 1990) and recently collected from 1997 to 2001 (Itoh et al, 2001, 2004). Besides the $\mathrm{E}, \mathrm{H}^{\circ}$, and $\mathrm{H}^{+}$strains, we have found several $\mathrm{E}^{\prime}$ strains that contain full-size hobo and/or deleted derivatives in older stocks and recently collected populations. We hypothesize about the date of the invasion and spread of hobo elements into Japanese Drosophila population. A novel phenotypic class $\left(\mathrm{H}^{\prime}\right.$ strain) was found in current Japanese populations. The locally characteristic defective hobo derivatives, yielding 1.6 and $1.8 \mathrm{~kb}$ XhoI fragments, that we call $J h$ elements may play regulatory role in the hobo system.

\section{Materials and methods}

\section{Flies}

Japanese natural populations of D. melanogaster collected between 1952 and 1989 were represented by eight isofemale lines (Hikone-R, Hikone-H, Eth-29 (Mino-H), Ashidakayama, Okaya, Asuka-1, Asuka-7, and Komagatani-30; Gamo et al, 1990) and three isogenic lines (Hikone-N2-1-1, -N4-3-3, and -N9-2-2; Nishino et al, 1993) maintained in our laboratory (Table 1). In 19972001, we established 126 isofemale lines of D. melanogaster that were collected from 11 localities in Honshu, the main island of Japan (KN (Katsunuma), FK (Fukui), MS (Mishima), IN (Inakadate), OS (Ohasama), HG (Higashine), NG (Niigata), OB (Obuse), OM (Okumura, Chichijima), TZ (Tozukawa), and TT (Tottori)); two localities in Hokkaido, the northernmost island of Japan (TY (Toyotomi) and SP (Sapporo); Itoh et al, 2004); and four localities in the Sakishima Islands, Okinawa, the southwesternmost islands of Japan (IS (Ishigaki), IR (Iriomote), HT (Hateruma), and YN (Yonaguni); Itoh
Table 1 Phenotypic characteristics in hobo system in older Japanese populations

\begin{tabular}{|c|c|c|c|c|}
\hline & $\begin{array}{c}\text { hobo- } \\
\text { activity } \\
\text { potential }^{\mathrm{a}}\end{array}$ & $\begin{array}{l}\text { hobo- } \\
\text { repression } \\
\text { potential }^{\text {b }}\end{array}$ & $\begin{array}{l}\text { hobo } \\
\text { status }\end{array}$ & $P-M$ status $^{\mathrm{c}}$ \\
\hline \multicolumn{5}{|l|}{ Controls } \\
\hline 23.5*/Cy (Greek) & 23 & 0 & $\mathrm{H}^{+}$ & Q \\
\hline Harwich (USA) & 0 & 23 & $E^{\prime}$ & $\mathrm{P}$ \\
\hline Oregon-R (USA) & 0 & 36 & $\mathrm{E}$ & M \\
\hline Canton-S (USA) & 0 & 32 & $\mathrm{E}$ & M \\
\hline \multicolumn{5}{|l|}{ Older Japanese population } \\
\hline 1952 Hikone-R & 0 & 70 & $\mathrm{E}$ & $\mathrm{M}$ \\
\hline 1957 Hikone-H & 2 & 0 & $\mathrm{H}^{\circ}$ & $\mathrm{Q}$ \\
\hline 1957 Eth-29 (Mino-H) & 0 & 0 & $\mathrm{H}^{\circ}$ & $\mathrm{M}$ \\
\hline 1961 Ashidakayama & 0 & 5 & $\mathrm{E}$ & $\mathrm{M}^{\prime}$ \\
\hline 1961 Okaya & 4 & 0 & $\mathrm{H}^{\circ}$ & $\mathrm{M}$ \\
\hline 1972 Asuka-1 & 2 & 0 & $\mathrm{H}^{\circ}$ & $\mathrm{M}^{\prime}$ \\
\hline 1972 Asuka-7 & 2 & 0 & $\mathrm{H}^{\circ}$ & $\mathrm{M}^{\prime}$ \\
\hline 1984 Komagatani-30 & 0 & 12 & $\mathrm{E}^{\prime}$ & Q \\
\hline 1989 Hikone-N 2-1-1 $^{\mathrm{d}}$ & 0 & 0 & $\mathrm{H}^{\circ}$ & $\hat{\mathrm{Q}}, \mathrm{P}$ \\
\hline 1989 Hikone-N 4-3-3 $^{\mathrm{d}}$ & 0 & 0 & $\mathrm{H}^{\circ}$ & $Q$ \\
\hline 1989 Hikone-N 9-2-2 ${ }^{\mathrm{d}}$ & 2 & 0 & $\mathrm{H}^{\circ}$ & $\mathrm{Q}$ \\
\hline
\end{tabular}

${ }^{a} \mathrm{GD}$ score in cross $\mathrm{A}$.

${ }^{\mathrm{b}} \mathrm{GD}$ score in cross $\mathrm{A}^{*}$.

cData of P-M status come from Gamo et al (1990).

${ }^{\mathrm{d}}$ There are isogenic lines and data of $\mathrm{P}-\mathrm{M}$ status come from Nishino et al (1993).

et al, 2001), as shown in Table 2. The P-M status was known from previous work for most of these lines (Tables 1 and 2). Canton-S and Oregon-R (both $M$ in the $\mathrm{P}-\mathrm{M}$ system) were used as $\mathrm{E}$ strain controls, and Harwich (strong $\mathrm{P}$ in the $\mathrm{P}-\mathrm{M}$ system) was used as the reference E strain in the hobo system. 23.5*/Cy was used as the reference $\mathrm{H}$ strain. 23.5* /Cy was provided by Dr G Yannopoulos; it bears one or more active hobo element on the second chromosome (Yannopoulos et al, 1987).

D. melanogaster strains were cultured at $25^{\circ} \mathrm{C}$ under standard laboratory conditions by mass culture on a cornmeal-glucose-yeast-agar medium (5\% cornmeal, $7 \%$ glucose, $5 \%$ dead yeast, $1 \%$ agar, and $0.35 \%$ propionic acid).

\section{GD sterility tests}

Harwich and $23.5^{*} / \mathrm{Cy}$ were used as the $\mathrm{E}$ and $\mathrm{H}$ reference strains, respectively, in the GD assays (Stamatis et al, 1989). Fifteen virgin individuals of each of the tested and reference strains were mated at $25^{\circ} \mathrm{C}$ to make two sets of A cross (Harwich $q+q \times$ tested $\hat{0} \hat{\sigma}$ ) and $A^{*}$ cross

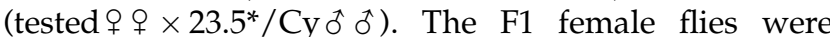
collected, allowed to mature for 3 days at $25^{\circ} \mathrm{C}$, and then dissected; at least 50 ovaries were scored. The percent of dysgenic ovaries $(100 \times$ (number of dysgenic ovaries/total number of dissected ovaries)) was calculated for each cross. In the $\mathrm{A}^{*}$ cross, the GD score was estimated by subtraction of the percent dysgenesis of Cy/tested F1 females from that of $23.5^{*} /$ tested ones ((GD percent of $23.5^{*} /$ tested)-(GD percent of Cy/tested)). Cross A measures hobo-activity potential of a tested strain and cross $\mathrm{A}^{*}$ measures hobo-repression potential (Figure 1a).

\section{Southern blot analysis}

Genomic DNA was extracted from 50 flies of each strain and then digested with the restriction enzyme XhoI. 
Table 2 Phenotypic characteristics of hobo system in current Japanese populations. (a) Honshu and Hokkaido and (b) Sakishima Islands, Okinawa

\begin{tabular}{|c|c|c|c|c|c|c|c|}
\hline \multirow[t]{2}{*}{ Year } & \multirow[t]{2}{*}{ Place } & \multicolumn{5}{|c|}{ Phenotypes of hobo element } & \multirow[t]{2}{*}{$\overline{P-M}$ status } \\
\hline & & $H^{+}$ & $H^{\circ}$ & $E^{\prime}$ & $H^{\prime}$ & Total & \\
\hline \multicolumn{8}{|c|}{$\begin{array}{l}\text { Locality in Japan (North to South) } \\
\text { (a) Honshu and Hokkaido }\end{array}$} \\
\hline 2000 & TY (Hokkaido) & 2 & 7 & 1 & & 10 & $\mathrm{P}, \mathrm{Q}, \mathrm{M}^{\prime}$ \\
\hline 2000 & SP (Hokkaido) & 4 & 5 & 1 & & 10 & $\mathrm{P}, \mathrm{Q}, \mathrm{M}^{\prime}, \mathrm{P}^{\prime}$ \\
\hline 2000 & IN (Aomori) & 2 & 12 & 1 & & 15 & $\mathrm{P}, \hat{\mathrm{Q}}, \mathrm{M}^{\prime}$ \\
\hline 2000 & OS (Iwate) & & 9 & & & 9 & $\mathrm{P}, \mathrm{Q}, \mathrm{P}^{\prime}$ \\
\hline 2000 & HG (Yamagata) & 3 & 6 & & & 9 & $\mathrm{P}, \mathrm{Q}, \mathrm{M}^{\prime}$ \\
\hline 2000 & NG (Niigata) & 1 & 8 & & & 9 & $\mathrm{Q}, \mathrm{M}^{\prime}$ \\
\hline 1997 & KN (Yamanashi) & & 1 & 1 & & 2 & $\mathrm{Q}, \mathrm{M}^{\prime}$ \\
\hline 1999 & FK (Fukui) & 2 & 5 & & & 7 & $\mathrm{Q}, \mathrm{M}^{\prime}$ \\
\hline 1999 & MS (Shizuoka) & & 2 & & & 2 & ND \\
\hline 2000 & OB (Nagano) & 1 & 3 & & & 4 & ND \\
\hline 2000 & TZ (Nara) & 2 & 8 & & & 10 & $\mathrm{Q}, \mathrm{M}^{\prime}$ \\
\hline 2001 & TT (Tottori) & & 9 & & & 9 & $\mathrm{P}, \mathrm{Q}, \mathrm{P}^{\prime}$ \\
\hline \multirow[t]{2}{*}{2000} & OM (Chichi-jima, Tokyo) & 2 & 4 & 1 & 1 & 8 & $\mathrm{Q}, \mathrm{M}^{\prime}$ \\
\hline & Subtotal & 19 & 79 & 5 & 0 & 104 & \\
\hline \multicolumn{8}{|c|}{ (b) Sakishima Islands, Okinawa } \\
\hline 1997 & IS (Ishigaki) & 3 & 1 & & & 4 & $P, Q$ \\
\hline 1998 & IR (Iriomote) & 7 & 1 & & & 8 & $\mathrm{P}, \mathrm{Q}, \mathrm{P}^{\prime}$ \\
\hline 1998 & HT (Hateruma) & 1 & & & 4 & 5 & $P, Q$ \\
\hline \multirow[t]{2}{*}{1998} & YN (Yonaguni) & 3 & 2 & & & 5 & $\mathrm{P}, \mathrm{Q}, \mathrm{M}^{\prime}$ \\
\hline & Subtotal & 14 & 4 & 0 & 4 & 22 & \\
\hline Total & & 33 & 83 & 4 & 6 & 126 & \\
\hline Percent & & 26 & 66 & 3 & 5 & 100 & \\
\hline
\end{tabular}

${ }^{\mathrm{a}}$ Data of $\mathrm{P}-\mathrm{M}$ status come from Itoh et al (2004) and ND represents no data.

a

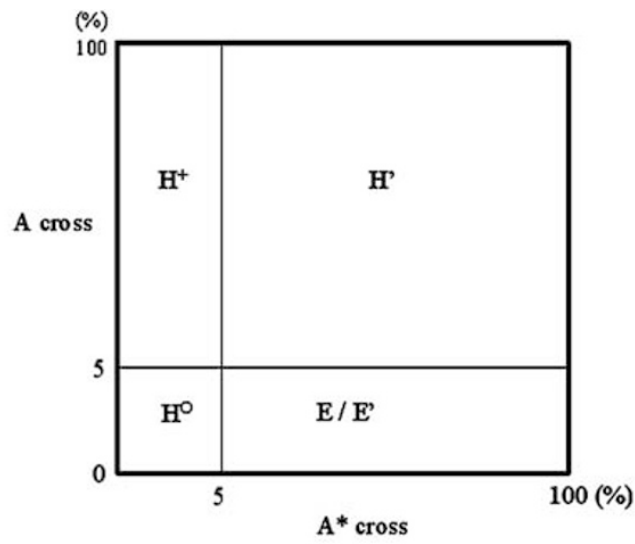

b

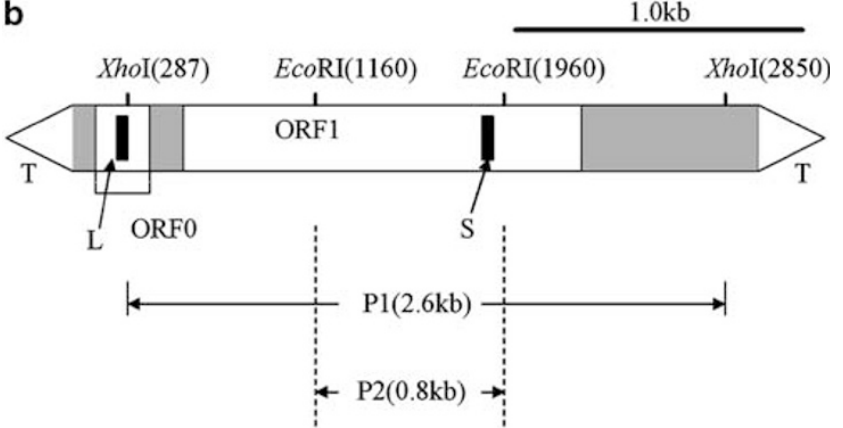

Figure 1 (a) Classes of hobo strains based on GD sterility tests. (b) Structure of a functional hobo element, HFL1 (Calvi et al, 1991). XhoI and EcoRI endonuclease cleavage sites and the fragments they generate are indicated.
About $5 \mu \mathrm{g}$ of digested DNA were electrophoresed in a $1 \%$ agarose gel, capillary blotted onto a nitrocellulose membrane (Schleicher and Schuell), hybridized to a labeled probe consisting of the $2.6 \mathrm{~kb}$ XhoI fragment or the $0.86 \mathrm{~kb} E c o \mathrm{RI}$ fragment of the pH108 hobo element (Streck et al, 1986), provided by Dr Eiji Nitasaka (Figure $1 \mathrm{~b}$ ), and detected by ECL direct nucleic acid labeling and detection systems (Amersham Pharmacia Biotech UK limited).

\section{Results}

Genetic phenotypes of the hobo system in Japan

Table 1 shows the genetic phenotypes from GD sterility tests of the hobo system in older Japanese populations. Based on the percentage of GD sterility (Figure 1a), Hikone-R, Ashidakayama, and Komagatani-30 were classified as E strains (low hobo activity and low repression potency). The rest of the strains established in Japan in 1952-1989 were $\mathrm{H}^{\circ}$ (Table 1). Hikone- $\mathrm{H}$ (1957) is the oldest $\mathrm{H}$ strain from a Japanese population.

In the current populations from 13 localities of Honshu and Hokkaido, $\mathrm{H}^{\circ}$ strains are predominant $(76 \%)$, as shown in Table 2a. In five localities (HG, NG, FK, OB, and TZ), only $\mathrm{H}^{+}$and $\mathrm{H}^{\circ}$ strains were found. In $\mathrm{KN}$, an $\mathrm{E}^{\prime}$ strain accompanied an $\mathrm{H}^{\circ}$ strain. $\mathrm{H}^{+}, \mathrm{H}^{\circ}$, and $\mathrm{E}^{\prime}$ strains were mixed in TY, SP, IN, and $\mathrm{OM}$, and only $\mathrm{H}^{\circ}$ strains were found in OS, MS, and TT. One $\mathrm{H}^{\prime}$ strain was found in $\mathrm{OM}$ (Chichijima, Tokyo) with $\mathrm{H}^{+}, \mathrm{H}^{\circ}$, and $\mathrm{E}^{\prime}$ strains. 
Twenty-two strains from the Sakishima Islands, southwest of Japan (Table 2b), are classified as $14 \mathrm{H}^{+}$strains, four $\mathrm{H}^{\circ}$ strains, and no $\mathrm{E}^{\prime}$ strains. In addition, four HT isofemale lines demonstrate a novel phenotype, which is designated as $\mathrm{H}^{\prime}$ (Figure 1a). $\mathrm{H}^{\prime}$ strains have high hoboactivity potential and low hobo-repression potential, like the $\mathrm{P}^{\prime}$ strains hypothesized in the $\mathrm{P}-\mathrm{M}$ system (Quesneville and Anxolabehere, 1998) and found in a natural population by Itoh et al (2001).

\section{hobo elements in Japanese populations}

To determine the temporal distribution of hobo elements in older Japanese populations of D. melanogaster, Southern blot analysis was carried out by using the $2.6 \mathrm{~kb}$ XhoI fragment of the complete hobo element as a probe (Figure 2). We found two E strains, Ashidakayama (lane 1) and Hikone-R (lane 8), with no hobo elements, and one $\mathrm{E}^{\prime}$ strain, Komogatani-30 (lane 13), having full-size hobo elements and deletion derivatives, as did Harwich (lane 10). Almost all $\mathrm{H}^{\circ}$ strains had both complete $(2.6 \mathrm{~kb})$ and defective hobo sequences $(1.8,1.6$, and $1.1 \mathrm{~kb})$, but Eth-29 (lane 2) and Asuka-1 (lane 6) had only defective hobo derivatives, and Okaya (lane 5) contained only complete hobo elements. Hikone-H (lane 9), established in 1957, is the oldest $\mathrm{H}$ strain in Japanese populations. Among three isogenic strains (Hikone-N2-1-1 (lane 3), -N4-3-3 (lane 11), and -N9-2-2 (lane 12) (Nishino et al, 1993), there are differences in the patterns of hobo-hybridizing bands, and all three are different from the older line, Hikone-H. Hikone-H contains a majority of bands that are found in the three, suggesting that they were derived either from Hikone-H or from the same population as Hikone-H.

Southern blots analysis was also carried out in 126 recently established isofemale lines, also using the $2.6 \mathrm{~kb}$ XhoI fragment of the complete hobo element as a probe (Figure 1b). All lines examined had many hobo copies in their genomes (Figure 3). Besides the $2.6 \mathrm{~kb}$ XhoI fragment of full-sized hobo elements and the $1.1 \mathrm{~kb}$ fragments of the Th elements (Periquet et al, 1989a), lines from Honshu and Hokkaido also show 1.6 and $1.8 \mathrm{~kb}$ XhoI fragments (Figure 3). Furthermore, most of isofemale lines showed a $1.3 \mathrm{~kb}$ XhoI fragment apparently corresponding to the $1.7 \mathrm{~kb} K h$ element, described as characteristic of Korean populations (Kim and Kim, 1999).

Five $\mathrm{E}^{\prime}$ strains (from TY, SP, IN, OM, and $\mathrm{KN}$ ) and one $\mathrm{H}^{\prime}$ strain $(\mathrm{OM})$ have many hobo-related sequences, as do $\mathrm{H}^{\circ}$ and $\mathrm{H}^{+}$strains (see TY-10 in Figure 3 and IN-9 in Figure 5; others not shown). No specific fragments were observed to be typical for $\mathrm{E}^{\prime}, \mathrm{H}^{\circ}$, or $\mathrm{H}^{+}$strains. No clear relationship was found between hobo element profiles and phenotypic characteristics.

In Southern blots of the Sakishima Islands populations, all isofemale lines except one contained full-size hobo elements (Figure 4). Among the various defective hobo elements, 1.1 and $1.8 \mathrm{~kb}$ XhoI fragments were found in all strains. A $1.6 \mathrm{~kb}$ XhoI fragment was also observed in almost all isofemale lines from the Sakishima Islands. Twelve out of 22 Sakishima Islands isofemale lines, and lines from IS (lanes 1, 2, and 4), IR (lanes 5, 7, 8, and 10), HT (lanes 15-17), and YN (lanes 19 and 22), showed a $1.3 \mathrm{~kb}$ XhoI fragment corresponding to $K h$ elements (Kim and Kim, 1999). The $\mathrm{H}^{\circ}$ strains in IS (lane 3) and YN (lanes 18 and 19) have both complete and defective hobo elements, but IR (lane 7) has only defective hobo elements, as did Asuka-1 (Figure 2). Four $\mathrm{H}^{\prime}$ strains from HT (lanes 13 and 15-17) also have both complete and various defective hobo elements, as do $14 \mathrm{H}^{+}$strains from the Sakishima Islands.

\section{Locally characteristic deletion-derivative $\mathrm{Jh}$ elements in} Japanese populations

We detected 1.6 and $1.8 \mathrm{~kb}$ XhoI fragments in some older and almost all current Japanese populations

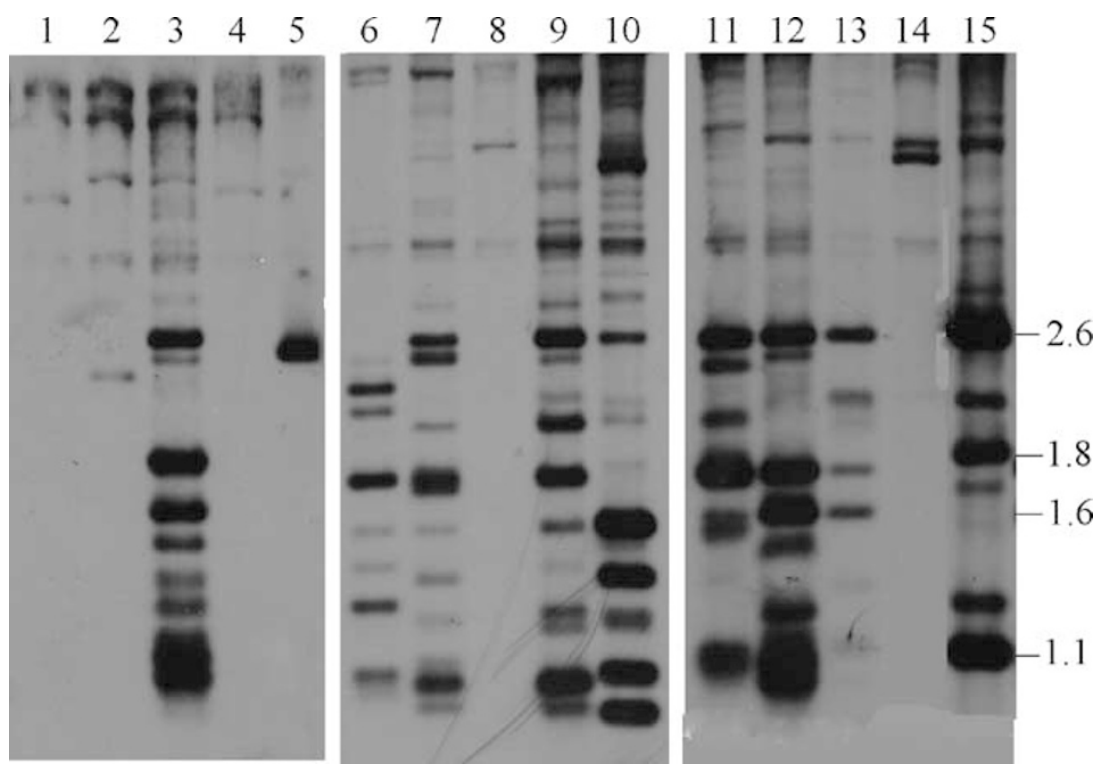

Figure 2 Southern blots of genomic DNA from older Japanese populations, probed with the XhoI fragment of the hobo element. The bands corresponding to full-length hobo elements ( $2.6 \mathrm{~kb}$ XhoI fragment), Th derivatives ( $1.1 \mathrm{~kb})$, and $J \mathrm{~h}$ elements (1.6 and $1.8 \mathrm{~kb})$ are indicated to the right. The strains are the following: lane 1, Ashidakayama; lane 2, Eth-29; lane 3, Hikone-N2-1-1; lane 4, Canton-S; lane 5, Okaya; lane 6, Asuka-1; lane 7, Asuka-7; lane 8, Hikone-R; lane 9, Hikone-H; lane 10, Harwich; lane 11, Hikone-N4-3-3; lane 12, Hikone-N9-2-2; lane 13, Komagatani-30; lane 14, Oregon-R; and lane 15, 23.5*/Cy. 

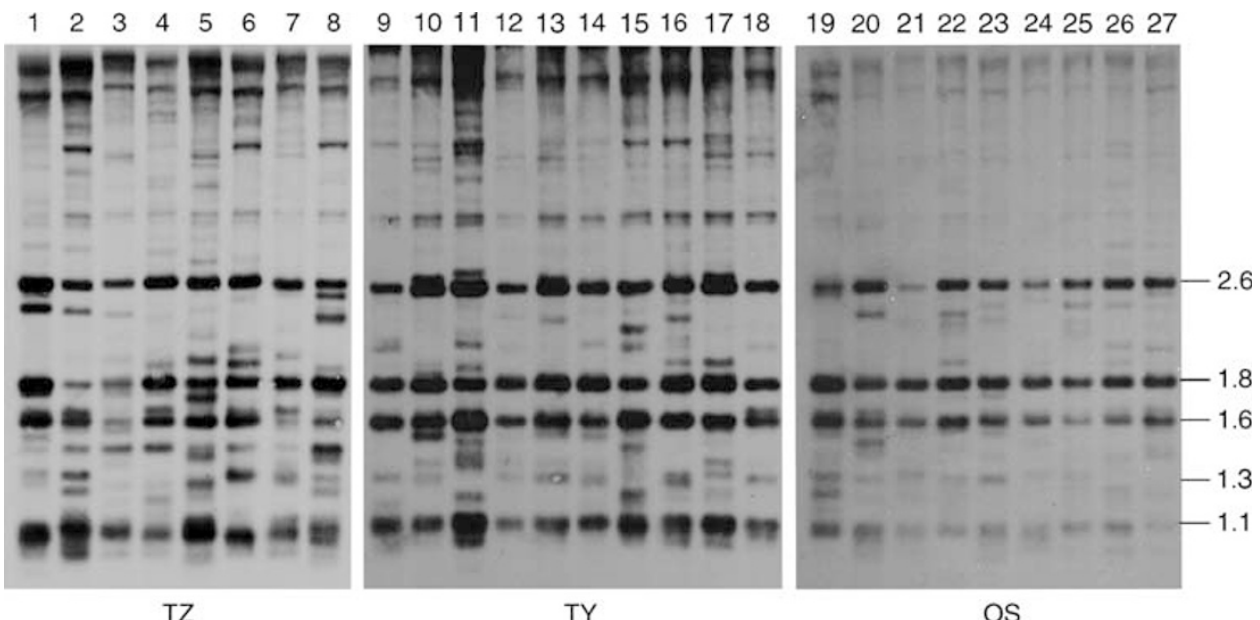

Figure 3 Southern blots of genomic DNA from current populations in Honshu and Hokkaido of Japan, probed with the XhoI fragment of the hobo element. The isofemale lines are: from Tozukawa (TZ, Nara) - lane 1, TZ-1 $\left(\mathrm{H}^{\circ}\right)$; lane 2, TZ-2 $\left(\mathrm{H}^{\circ}\right)$; lane 3, TZ-3 $\left(\mathrm{H}^{+}\right)$; lane 4, TZ-6 $\left(\mathrm{H}^{+}\right)$; lane 5, TZ-7 $\left(\mathrm{H}^{\circ}\right)$; lane 6, TZ-8 $\left(\mathrm{H}^{\circ}\right)$; lane 7, TZ-9 $\left(\mathrm{H}^{\circ}\right)$; lane 8, T-11 $\left(\mathrm{H}^{\circ}\right)$; from Toyotomi $(\mathrm{TY}$, Hokkaido $)-$ lane 9, TY-1 $\left(\mathrm{H}^{+}\right)$; lane 10 , TY-2 $\left(\mathrm{H}^{+}\right)$; lane 11, TY-3 $\left(\mathrm{H}^{\circ}\right)$; lane 12, TY-4 $\left(\mathrm{H}^{\circ}\right)$; lane 13, TY-5 $\left(\mathrm{H}^{\circ}\right)$; lane 14, TY-6 $\left(\mathrm{H}^{\circ}\right)$; lane 15, TY-7 $\left(\mathrm{H}^{\circ}\right)$; lane 16, TY-8 $\left(\mathrm{H}^{\circ}\right)$; lane 17, TY-9 $\left(\mathrm{H}^{\circ}\right)$; lane 18 , TY-10 ( $\mathrm{E}^{\prime}$ ); and from Ohasama (OS, Iwate) - all isofemale lines are $\mathrm{H}^{\circ}$; lane 19, OS-1; lane 20 OS-3; lane 21, OS-4; lane 22, OS-8; lane 23, OS-9; lane 24, OS-11; lane 25, OS-12; lane 26, OS-13; and lane 27, OS-14. Bands corresponding to $\mathrm{Kh}(1.3 \mathrm{~kb})$ and other elements are indicated to the right, as in Figure 2.
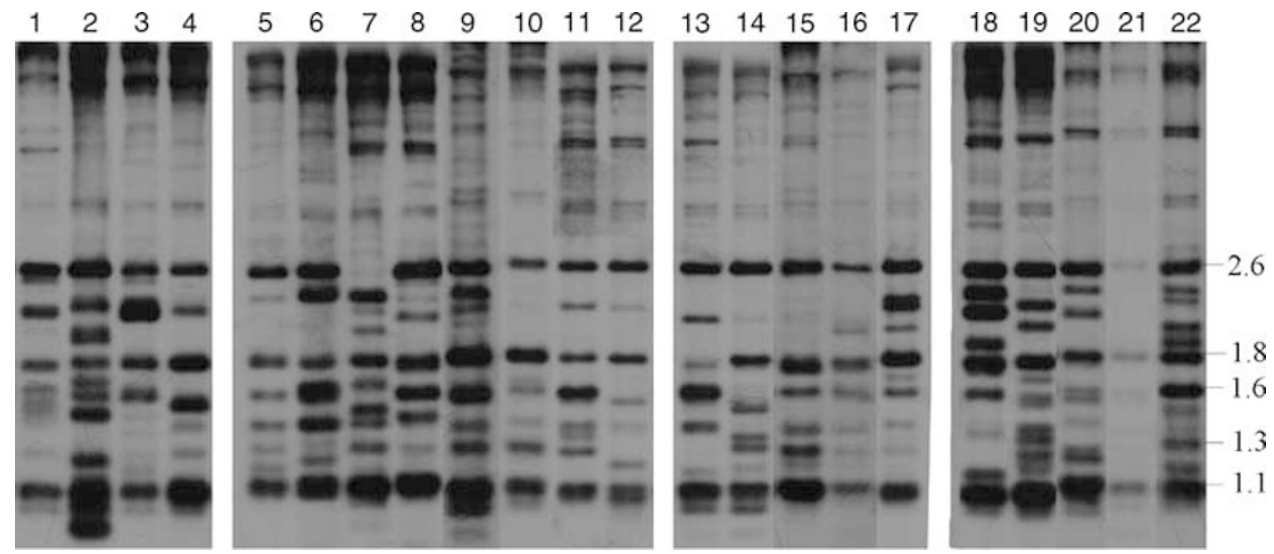

Figure 4 Southern blots of genomic DNA from the Sakishima Islands populations, probed with the XhoI fragment of the hobo element. The isofemale lines are: from Ishigaki (IS, Okinawa) - lane 1, IS-29 $\left(\mathrm{H}^{+}\right)$; lane 2, IS-32 $\left(\mathrm{H}^{+}\right)$; lane 3, IS-53 $\left(\mathrm{H}^{\circ}\right)$; lane 4, IS-55 $\left(\mathrm{H}^{+}\right)$; from Iriomote (IR, Okinawa) - lane 5, IR-1 $\left(\mathrm{H}^{+}\right)$; lane 6, IR-2 $\left(\mathrm{H}^{+}\right)$; lane 7, IR-3 $\left(\mathrm{H}^{\circ}\right)$; lane 8, IR-4 $\left(\mathrm{H}^{+}\right)$; lane 9, IR-12 $\left(\mathrm{H}^{+}\right)$; lane 10, IR-13 $\left(\mathrm{H}^{+}\right)$; lane 11, IR-14 ( $\left.\mathrm{H}^{+}\right)$; lane 12, IR-15 $\left(\mathrm{H}^{+}\right)$; from Hateruma (HT, Okinawa) - lane 13, HT-25 $\left(\mathrm{H}^{\prime}\right)$; lane 14, HT-26 $\left(\mathrm{H}^{+}\right)$; lane 15, HT-27 $\left(\mathrm{H}^{\prime}\right)$; lane 16 HT-28 $\left(\mathrm{H}^{\prime}\right)$; lane 17 , HT-29 $\left(\mathrm{H}^{\prime}\right)$; and from Yonaguni (YN, Okinawa) - lane 18, YN-1 $\left(\mathrm{H}^{\circ}\right)$; lane 19, $\mathrm{YN}-2\left(\mathrm{H}^{\circ}\right)$; lane 20, $\mathrm{YN}-3\left(\mathrm{H}^{+}\right)$; lane $21, \mathrm{YN}^{-4}\left(\mathrm{H}^{+}\right)$; and lane 22 , YN-5 $\left(\mathrm{H}^{+}\right)$. Bands corresponding to $K h(1.3 \mathrm{~kb})$ and other elements are indicated to the right, as in Figure 2.

(Figures 2-4). The 1.6 and $1.8 \mathrm{~kb}$ fragments, predicted to correspond to 2.0 and $2.2 \mathrm{~kb}$ internally deleted hobo derivatives, seem to be characteristic of Japanese populations, and we designate them as Jh elements. To characterize the deleted regions in these elements, Southern blot analysis was carried out using the $0.8 \mathrm{~kb}$ EcoRI fragment of the central region of a complete hobo element as a probe (Figure 1b). Nearly all the fragments smaller than the $1.6 \mathrm{~kb}$ bands almost disappeared, but the molecular fragments larger than the $1.8 \mathrm{~kb}$ bands remained clear (Figure 5b) in comparison with the Southern blot probed with the $2.6 \mathrm{~kb}$ of XhoI fragment (Figure 5a). This indicates that the $1.6 \mathrm{~kb}$ fragments have lost almost the entire EcoRI fragment of the central region of the complete hobo element, but that the $1.8 \mathrm{~kb}$ bands can hybridize to the probe because their defects are smaller than the EcoRI fragment.
Higher molecular weight XhoI fragments $(>2.6 \mathrm{~kb})$ of hobo-hybridizing sequences were detected in all tested strains, including E strains (Figures 2 and 5a). These fragments have also lost almost the entire EcoRI fragment since most such bands disappeared when probed with the $0.8 \mathrm{~kb}$ EcoRI fragment of a complete hobo element (Figure 5b).

\section{Discussion}

In this study, we describe two aspects of hobo elements in Japanese $D$. melanogaster populations. We first identify when hobo elements invaded and how they spread through the populations, and second, we have identified two deleted forms of hobo unique to Japanese populations. We found no hobo elements in the Hikone-R strain, collected in 1952, but we did detect them in the Hikone- 

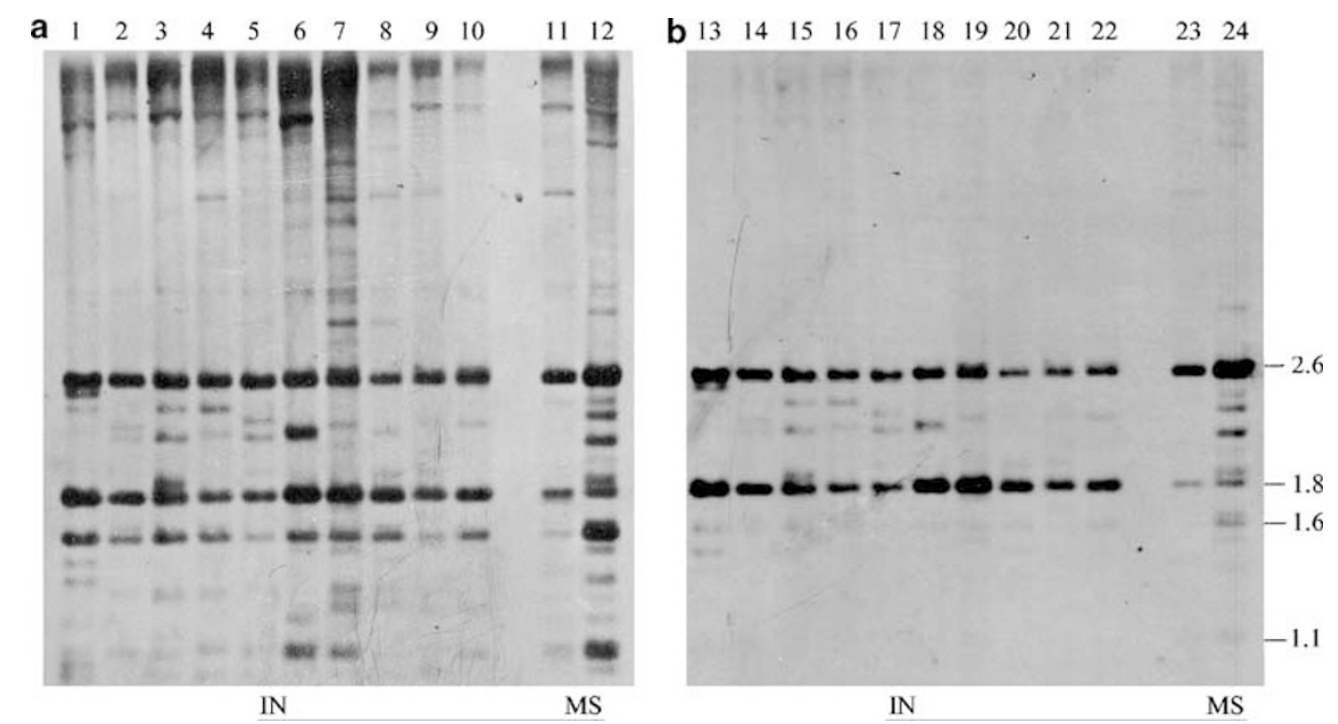

Figure 5 Southern blots of genomic DNA from Inakadate (IN, Aomori) and Mishima (MS, Shizuoka) populations. (a) The XhoI fragment of the hobo element is used as a probe from lanes 1 to 12 . (b) The EcoRI fragment is used as a probe (Figure $1 \mathrm{~b}$ ) from lanes 13 to 24 . The isofemale lines are: lane 1, IN-1 $\left(\mathrm{H}^{\circ}\right)$; lane 2, IN-3 $\left(\mathrm{H}^{\circ}\right)$; lane 3, IN-4 $\left(\mathrm{H}^{\circ}\right)$; lane 4, IN-6 $\left(\mathrm{H}^{+}\right)$; lane 5, IN-8 $\left(\mathrm{H}^{+}\right)$; lane 6, IN-9 $\left(\mathrm{E}^{\prime}\right)$; lane 7, IN-11 $\left(\mathrm{H}^{\circ}\right)$; lane 8 , IN-14 $\left(\mathrm{H}^{\circ}\right)$; lane 9, IN-15 $\left(\mathrm{H}^{\circ}\right)$; lane 10, IN-17 $\left(\mathrm{H}^{\circ}\right)$; lane 11, MS-7 $\left(\mathrm{H}^{\circ}\right)$; and lane 12, MS-53 $\left(\mathrm{H}^{\circ}\right)$. Lanes 13-24 are the same samples as lanes 1-12. Fragment sizes are indicated as in Figure 2.

$\mathrm{H}$ and Mino-H strains, collected in 1957. This is consistent with the hypothesis that hobo transposable elements invaded the D. melanogaster genome in the mid1950s in America, France, USSR, China, and Africa (Periquet et al, 1989a, b, 1990; Boussy and Daniels, 1991; Pascual and Periquet, 1991). Around 1950, in HikoneCity large quantities of DDT and pyrethrum were used for several years to kill mosquitoes for malaria control, and the insecticide-resistant strain, Hikone-R $(\mathrm{E})$, was isolated (Ogaki and Tsukamoto, 1953). On the hottest days of the summer, the heat tolerant $\mathrm{H}^{\circ}$ strains, Hikone$\mathrm{H}$ and Mino-H, were collected (Ogaki, 1962). We imagine that environmental changes could contribute to the invasion and spread of hobo elements, although exactly how is an open question. When complete hobo elements were introduced into the Hikone (E) strain, most of the transgenic strains at 14 generations showed a certain degree of hobo-activity and -repression potential, and these plateaued by generation 50 at $25^{\circ} \mathrm{C}$. The spread of hobo elements was dependent on culture temperature (Galindo et al, 1995). Gamo et al (1990) showed that Hikone-R and Mino-H both lack $P$ elements but that Hikone-H has $P$ elements. Both $P$ and hobo transposable elements seem to have invaded the genome in the mid1950s in at least the central region of Japan.

This study also revealed that $\mathrm{H}^{\circ}$ strains are predominant in current Japanese populations of D. melanogaster, but that a high proportion of $\mathrm{H}^{+}$strains occurs in the Sakishima Islands, Okinawa. The first discoveries of $\mathrm{H}^{\prime}$ strains in natural populations were from Hateruma (the Sakishima Islands) and Chichijima $(1000 \mathrm{~km}$ south of Tokyo metropolitan). This novel type of hobo strain, $\mathrm{H}^{\prime}$, was described from transgenic experiments (Galindo et al, 1995). Following introduction of a full-size hobo element, the experimental populations were $\mathrm{E}^{\prime}$ until 14 generations, became $\mathrm{H}^{\prime}$, and eventually evolved an $\mathrm{H}^{+}$ or an $\mathrm{H}^{\circ}$ phenotype. If a similar pattern occurs in natural populations, hobo elements may have recently invaded D. melanogaster populations in Hateruma and Chichijima, and these populations would be expected to evolve to $\mathrm{H}^{+}$and $\mathrm{H}^{\circ}$. Therefore, these populations appear to be in an evolutionarily early phase of hobo invasion. We speculate that hobo elements invade to the central region of Japan and subsequently spread to the far islands, and that hobo elements in Japanese populations are at intermediate, nonequilibrium, evolutionary stages.

The second remarkable character of the hobo system in Japanese populations is the presence of 1.8 and $1.6 \mathrm{~kb}$ XhoI fragments in Southern blots, corresponding to 2.2 and $2.0 \mathrm{~kb}$ hobo sequences. The deletion of the $1.6 \mathrm{~kb}$ fragments is the central portion of the full-sized element. The 2.2 and $2.0 \mathrm{~kb}$ deleted hobo elements have not been obviously present in the surveys of populations from other countries (Periquet et al, 1989a, b, 1990; Boussy and Daniels, 1991; Pascual and Periquet, 1991; Kim and Kim, 1999). Therefore, they seem to be defective hobo derivatives unique to Japanese Drosophila populations. We call them Jh elements. Souames et al (2003b) reported that $1.8 \mathrm{~kb}$ XhoI fragments appeared independently at different generations in lines transformed with complete hobo elements. In two lines, the introduction of a hobo element did not trigger a multiplicative invasion of the genome, but $1.8 \mathrm{~kb}$ fragments appeared (Souames et al, 2003b). This study also gives evidence that $1.8 \mathrm{~kb}$ deleted elements may be involved in regulating the activity of the hobo elements in natural population. $\mathrm{H}^{\circ}, \mathrm{H}^{+} \mathrm{H}^{\prime}$, and $\mathrm{E}^{\prime}$ strains in the current Japanese natural populations have predominantly $T h$ elements $(1.5 \mathrm{~kb}$; Periquet et al, 1989a; Pascual and Periquet, 1991) as well as full-size hobo elements and $t h$ elements $(1.6$ and $1.8 \mathrm{~kb}$ XhoI fragments). Th elements are present in most strains from different continents (Periquet et al, 1990). The wide distribution and predominance of the Th elements suggest that they might be analogous to the KP elements 
of the P-M system (Black et al, 1987; Jackson et al, 1988; Itoh et al, 2001, 2004), perhaps even to having a regulatory role. Another defect hobo element, the Kh element of $1.7 \mathrm{~kb}$, a specific defective element described from Korean strains (Kim and Kim, 1996, 1999), was found in most Japanese populations. When complete hobo elements invaded $\mathrm{E}$ genomes in experimental populations, they evolved to one of three patterns: only full-size hobo sequences; only deleted derivatives; or both full-size and deleted hobo sequences (Souames et al, 2003a). The first pattern is seen in Okaya (1961) in Figure 2 (lane 5), the second pattern is seen in Eth-29 (Mino-H, 1957) and Asuka-1 (1972) in Figure 2 (lanes 2 and 6) and IR (1998) in Figure 4 (lane 6), and the third pattern is seen in almost all the rest of the tested strains. The presence of a full-length hobo element capable of producing active transposase would seem to be required for transposition and GD sterility, but the presence of repression ability in some strains that lack full-length hobo sequences suggests that internally deleted elements may be able to play a role in repression.

When genomic DNAs are analyzed by Southern blots, high molecular weight XhoI fragments of hobo-hybridizing sequences are detected in all current strains of $D$. melanogaster (Boussy and Daniels, 1991; Boussy and Itoh, 2004; this study). We note that they generally seem to lack the homologous sequences in the central region of complete hobo elements.

Pascual and Periquet (1991) reported that the hobo elements are very variable in laboratory stocks and can be lost in a few decades. In our GD sterility test, the $23 \%$ GD sterility we observed for the control cross, o o Harwich $\times 23.5^{*} / \mathrm{Cy}^{*} \sigma^{*}$, is lower than that found by others (Yannopoulos et al, 1987; Pascual and Periquet, 1991). They used Harwich ${ }^{Y}$ (an $E^{\prime}$ strain) and we used Harwich (also an $\mathrm{E}^{\prime}$ strain) maintained in our laboratory since 1986, but the original Harwich strain (USA) is described as an $\mathrm{H}^{\circ}$ strain (Pascual and Periquet, 1991). Both Harwich ${ }^{Y}$ and our Harwich appear to represent changes of phenotype over time from $\mathrm{H}$ to $\mathrm{E}^{\prime}$.

\section{References}

Bigot YC, Auge-Gouillou C, Periquet G (1996). Computer analyses reveal a hobo-like element in the nematode Caenorhabditis elegans, which presents a conserved transposase domain common with the TcI-mariner transposon family. Gene 174: 265-271.

Black DM, Jackson MS, Kidwell MC, Dover GA (1987). KP elements repress P-induced hybrid dysgenesis in Drosophila melanogaster. EMBO J 6: 4125-4135.

Blackman RK, Grimaila R, Koehler MMD, Gelbart WM (1987). Mobilization of hobo elements residing within the decapentaplegic gene complex: suggestion of a new hybrid dysgenesis system in Drosophila melanogaster. Cell 49: 497-505.

Boussy IA, Daniels SB (1991). hobo transposable elements in Drosophila melanogaster and D. simulans. Genet Res 58: 27-34.

Boussy IA, Itoh M (2004). Wanderings of hobo: a transposon in Drosophila melanogaster and its close relatives. Genetica 120: 125-136.

Boyle L, O’Neill SL, Robertson HM, Karr TL (1993). Interspecific and intraspecific horizontal transfer of Wolbachia in Drosophila. Science 260: 1796-1799.

Calvi BR, Hong TJ, Findley SD, Gelbart WM (1991). Evidence for a common evolutionary origin of inverted repeat transposons in Drosophila and plants: hobo, Activator, and Tam3. Cell 66: 465-471.
Daniels SB, Chovnick A, Boussy IA (1990). Distribution of hobo elements in the genus Drosophila. Mol Biol Evol 7: 589-606.

Finnegan DJ (1992). Transposable elements. In: Lindsley DL, Zimm GG (eds) The Genome of Drosophila melanogaster. Academic Press, Inc.: New York. pp 1096-1107.

Galindo MI, Bigot Y, Sánchez MD, Periquet G, Pascual L (2001). Sequences homologous to the hobo transposable element in E strains of Drosophila melanogaster. Mol Biol Evol 18: 1532-1539.

Galindo MI, Ladevèze V, Lemeunier F, Kalmes R, Periquet G, Pascual L (1995). Spread of the autonomous transposable element hobo in the genome of Drosophila melanogaster. Mol Biol Evol 12: 723-734.

Gamo S, Sakajo M, Ikeda K, Inoue Y, Sakoyama Y, NakashimaTanaka E (1990). Temporal distribution of $\mathrm{P}$ elements in Drosophila melanogaster strains from natural populations in Japan. Jpn J Genet 65: 277-285.

Itoh M, Fukui T, Kitamura M, Uenoyama T, Watada M, Yamaguchi M (2004). Phenotypic stability of the P-M system in wild populations of Drosophila melanogaster. Genes Genet Syst 79: 9-15.

Itoh M, Sasai N, Inoue Y, Watada M (2001). P elements and P-M characteristics in natural populations of Drosophila melanogaster in the southernmost islands of Japan and in Taiwan. Heredity 86: 206-212.

Jackson MS, Black DM, Dover GA (1988). Amplification of KP elements associated with the repression of hybrid dysgenesis in Drosophila melanogaster. Genetics 120: 1003-1013.

Kidwell MG (1979). Hybrid dysgenesis in Drosophila melanogaster. The relationship between the $\mathrm{P}-\mathrm{M}$ and I-R interaction systems. Gene Res 33: 205-217.

Kim JM, Kim W (1996). Hybrid dysgenesis and distribution of hobo elements in Korean populations of Drosophila melanogaster. Korean J Genet 18: 83-92.

Kim JM, Kim W (1999). Identification of a full-size hobo element and deletion-derivatives in Korean populations of Drosophila melanogaster. Mol Cells 9: 127-132.

Ladeveze V, Aulard S, Chaminade N, Biémont C, Periquet G, Lemeunier F (2001). Dynamics of the hobo transposable element in transgenic lines of Drosophila melanogaster. Genet Res 77: 135-142.

Ladeveze V, Galindo MI, Chaminade N, Pascal L, Periquet G, Lemeunier F (1998). Transmission pattern of hobo transposable element in transgenic lines of Drosophila melanogaster. Genet Res 71: 97-107.

Lim JK (1979). Site-specific instability in Drosophila melanogaster: the origin of the mutation and cytogenetic evidence for site specificity. Genetics 93: 681-701.

McGinnis W, Shermoen AW, Beckendorf SK (1983). A transposable element inserted just $5^{\prime}$ to a Drosophila glue protein gene alters gene expression and chromatin structure. Cell 34 : 75-84.

Nishino A, Murata T, Inoue Y, Sakoyama Y, Nakashima-Tanaka E, Gamo S (1993). Phenotypic and structural variations in P-M system of Drosophila melanogaster in Japanese natural populations. Genet (Life Sci Adv) 12: 131-137.

Ogaki M (1962). Inheritance of heat tolerance in D.melanogaster. Drosophila Inform Serv 36: 103.

Ogaki M, Tsukamoto M (1953). Genetical analysis of DDTresistance in some Japanese strains of Drosophila melanogaster. Botyu-Kagaku 18: 100-104.

Pascual L, Periquet G (1991). Distribution of hobo transposable elements in natural populations of Drosophila melanogaster. Mol Biol Evol 8: 282-296.

Periquet G, Hamelin M, Bigot Y, Hu K (1989a). Presence of the deleted hobo element Th in Eurasian populations of Drosophila melanogaster. Genet Sel Evol 21: 107-111.

Periquet G, Hamelin M, Bigot Y, Lepissier A (1989b). Geographical and historical patterns of distribution of hobo elements in Drosophila melanogaster populations. J Evol Biol 2: 223-229.

Periquet G, Hamelin MH, Kalmes R, Eeken J (1990). Hobo elements and their deletion-derivative sequences in Droso- 
phila melanogaster and its sibling species D.simulans, D.mauritiana and D.sechellia. Genet Sel Evol 22: 393-402.

Quesneville H, Anxolabehere D (1998). Dynamics of transposable elements in metapopulations: a model of $\mathrm{P}$ element invasion in Drosophila. Theor Popul Biol 54: 175-193.

Souames S, Bonnivard E, Bazin C, Higuet D (2003a). High mutation rate of TPE repeats: a microsatellite in the putative transposase of the hobo element in Drosophila melanogaster. Mol Biol Evol 20: 1826-1832.

Souames S, Bazin C, Bonnivard E, Higuet D (2003b). Behavior of the hobo transposable element with TPE repeats in transgenic lines of Drosophila melanogaster. Mol Biol Evol 20: 2055-2066.

Stamatis N, Monastirioti M, Yannopoulos G, Grigliatti TA (1989). The P-M and the 23.5MRF (hobo) systems of hybrid dysgenesis in Drosophila melanogaster are independent of each other. Genetics 123: 379-387.
Streck RD, MacGaffey JE, Beckendorf SK (1986). The structure of hobo transposable elements and their insertion sites. EMBO J 5: 3615-3623.

Warren WD, Atkinson PW, O'Brochta DA (1994). The Hermes transposable element from the housefly, Musca domestica, is a short inverted repeat-type element of the hobo, Ac and Tam3 (hAT) element family. Genet Res Cam 64: 87-97.

Yannopoulos G, Stamatis N, Zacharopoulou A, Pelecanos M (1983). Site specific breaks induced by the male recombination factor 23.5 MRF in Drosophila melanogaster. Mutat Res 108: 185-202.

Yannopoulos G, Stamatis N, Monastiriote M, Hatzopoulos P Louis C (1987). hobo is responsible for the induction of hybrid dysgenesis by strains of Drosophila melanogaster bearing the male recombination factor $23.5 M R F$. Cell 49 : 487-495. 